\title{
Práticas de ensino-aprendizagem com base em cenários reais na formação superior em inclusão
}

\author{
Catarina Mangas ${ }^{a}$, Jenny Sousa ${ }^{b}$ \\ ${ }^{a}$ ESECS, CICS.NOVA - iACT/CI\&DEI, Politécnico de Leiria, Portugal. catarina.mangas@ipleiria.pt \\ ${ }^{\mathrm{b}}$ ESECS, CICS.NOVA - iACT/CI\&DEI, Politécnico de Leiria, Portugal. jenny.sousa@ipleiria.pt
}

\begin{abstract}
Resumo
Estudar a inclusão implica conhecer e explorar diversas áreas do conhecimento em função das relações e intercâmbios entre pessoas, grupos e organizações sociais. $O$ Mestrado em Comunicação Acessível do Politécnico de Leiria (Portugal), ao olhar de forma holística para o individuo, procura aproximar os estudantes da realidade com que se confrontarão na sua vida profissional, apresentando uma panorâmica abrangente das perspetivas sob as quais se podem abordar questões de deficiência em todos os domínios da vida pessoal e social. Para o efeito, procura-se adotar, nas suas Unidades Curriculares, práticas de ensino-aprendizagem que permitam a exploração, reflexão e análise de problemas e cenários reais.
\end{abstract}

$O$ artigo apresenta o caso concreto da Unidade Curricular de Inclusão na Educação, Profissão e Lazer, em que, a partir dos conhecimentos teóricos adquiridos, se espera que os estudantes possam identificar as necessidades de pessoas que apresentam os quatro domínios da deficiência (motora, intelectual, auditivo e visual) e as condicionantes dos contextos que frequentam, delineando possiveis soluções.

Este trabalho é realizado em pequenos grupos e tem por base um relatório descritivo das funções e estruturas do corpo, das atividades e participação e dos fatores ambientais inerentes a um jovem trabalhador-estudante que apresenta deficiência. A partir deste documento, pretende-se simular um serviço de consultoria técnico-cientifica que envolva profissionais de diversas áreas, tendo por base a legislação nacional e as normas internacionais que regulamentam os direitos e os deveres da pessoa com deficiência no âmbito da educação, da inclusão no mercado de trabalho e no acesso à cultura e ao lazer.

Palavras-chave: Ensino Superior, Inclusão, Cenários reais; Metodologia baseada em problemas 


\section{Introdução}

Ao chegar ao fim da segunda década do século XXI, e perante os tempos de instabilidade e imprevisibilidade que atravessamos, torna-se premente equacionar a forma como as instituições de Ensino Superior podem contribuir para conhecer e intervir sobre a realidade atual.

Uma das possibilidades, é a transposição dos contextos reais para os espaços formativos, através da implementação de metodologias ativas e inovadoras, que potenciem a reflexão do estudante em torno de problemas e necessidades da sociedade pós-moderna.

O propósito deste artigo não é o de detalhar as metodologias ativas passíveis de aplicação no Ensino Superior, não só pelo facto de serem inúmeras e bastante diversificadas, mas também em função do espaço disponível para a apresentação do texto, mas essencialmente o de relatar uma experiência concreta em que foi aplicada a metodologia de ensinoaprendizagem baseada em problemas e cenários reais, refletindo sobre as opções tomadas.

Trata-se do caso da Unidade Curricular de Inclusão na Educação, Profissão e Lazer, do Mestrado em Comunicação Acessível, que contempla uma atividade, a realizar em grupo, em que são apresentados casos de pessoas reais, que apresentam deficiência, procurando-se que os estudantes reflitam sobre eventuais soluções de acessibilidade e inclusão dirigidas a essas pessoas, nos vários contextos da sua vida diária.

\section{Formação superior para a inclusão}

A inclusão diz respeito, de forma genérica, a um processo através do qual a sociedade se adapta para acolher, reconhecer e valorizar todas as pessoas, independentemente do seu perfil de funcionalidade (Sassaki, 2009).

Segundo o autor, apesar de ser um desígnio das sociedades modernas, que engloba questões políticas, sociais e culturais, a plena inclusão ainda não é uma realidade, já que prevalecem barreiras físicas e atitudinais que continuam a colocar alguns, em particular as pessoas com deficiência, numa situação fragilizada, agudizando a sua já debilitada condição humana e social (Sassaki, 2009).

Face a esta realidade, o desafio da inclusão exige iniciativas de intervenção concreta e contextualizada, que reduzam qualquer ação discriminatória, potenciando o acesso e o usufruto de todos os locais e serviços da comunidade:

- Ahieving the inclusion and full participation of children and adults with 
disabilities in the society requires a twin track approach comprising both disability-inclusive and disability-specific initiatives. In other words, while public policies and development programs must include a disability perspective and be fully accessible to persons with disabilities, disability specific needs and situations must also be addressed through targeted interventions in order to enable access to mainstream development processes." (Skoog, 2017, p. 349)

Estas iniciativas têm, necessariamente, de ser implementadas por profissionais que detenham conhecimentos científicos consistentes, mas que não descurem as necessidades específicas das pessoas com quem trabalham, em função do seu perfil individual (Omete, 2018). Neste sentido, é imprescindível que o Ensino Superior seja especializado, mas, em simultâneo, transdisciplinar e pragmático, potenciando não só os saberes dos estudantes, mas também a sua capacidade de compreender e agir nos diversos contextos sociais.. Só assim é possível que os profissionais se sintam comprometidos com a intenção de contribuírem para o pleno exercício dos direitos sociais e humanos dos cidadãos com deficiência.

Para que tal aconteça, é necessário que as instituições de ensino abandonem, definitivamente, as metodologias mais tradicionalistas, em que o professor e o seu conhecimento magistral eram o cerne do processo de ensino-aprendizagem, dando lugar a contextos educativos em que o estudante tem um papel ativo na construção do seu conhecimento (Mangas, 2020; Mizokami, 2018).

Ao entender o estudante como agente principal do processo de ensino-aprendizagem, desencadeia-se um conjunto de necessárias modificações, que vão desde a definição dos objetivos das disciplinas, à forma como os conteúdos programáticos são abordados, ou seja, à metodologia que é adotada em sala de aula (Dias, 2016).

É neste contexto que surgem as estratégias mais práticas e estimulantes, que procuram que os estudantes interajam colaborativamente, construindo verdadeiras comunidades de aprendizagem. Nestas, é permitido que cada um possa individualmente, e em conjunto com os demais, (re)criar relações entre os conhecimentos prévios e as novas informações, potenciando a capacidade de aprender a aprender (Barkley, 2018; Moran, 2015).

\section{Metodologia de ensino-aprendizagem baseada em problemas e cenários reais}

As investigações têm demonstrado que as pedagogias mais ativas proporcionam melhores resultados na avaliação, maior motivação para com o percurso académico e, até, uma menor probabilidade de abandono escolar precoce (Burke, 2011; Hassanien, 2006). Por outro lado, 
tem-se verificado que as entidades empregadoras valorizam mais aqueles que apresentam competências que são construídas através destas metodologias, nomeadamente capacidades de comunicação, bom relacionamento interpessoal e de trabalho em equipa (Suleman, 2016).

A metodologia de ensino-aprendizagem baseada em problemas surge como uma opção que vai ao encontro destas premissas, por permitir que os estudantes aprendam através da resolução de uma determinada questão presente num contexto específico (Yew \& Goh, 2016).Essa questão é o elemento despoletador de um conjunto de etapas, que vão desde a análise das necessidades do contexto em estudo, à identificação da informação necessária, que vai potenciar a realização de pesquisas autónomas e a discussão/brainstorming de ideias, culminando depois, em sugestões de potenciais soluções (Ulger, 2018). O processo repete-se, numa lógica cíclica, tantas vezes quantas forem necessárias, até serem alcançadas as melhores soluções que colmatem as necessidades dos sujeitos envolvidos e dos contextos em que estão inseridos.

Ao longo deste processo, cada estudante assume a responsabilidade pela gestão da sua aprendizagem, que implica um trabalho colaborativo em pequenos ou grandes grupos, orientados pelo professor que perde o lugar central de outrora (Hallinger \& Bridges, 2016). A este cabe agora a posição de mediador do conhecimento, que direciona o trabalho a desenvolver, dando feedback formativo. Ao invés de dogmas fundamentais e incontestáveis, o orientador vai colocando questões aos estudantes, que potenciam a memorização do conhecimento adquirido e estimulam o pensamento crítico e reflexivo na procura de soluções criativas (Ulger, 2018). Esta descoberta autónoma, mas orientada, contribui para que os formandos desenvolvam competências que lhes permitam, na sua atividade profissional, fazer analogias com novos contextos/problemas (Yew \& Goh, 2016).

A partir do que foi exposto, facilmente se percebe que metodologias baseadas em resolução de problemas são contextos privilegiados nos percursos formativos de nível superior. Neste sentido, é fundamental que os problemas sejam selecionados de forma criteriosa, em função dos conteúdos programáticos das Unidades Curriculares mas, principalmente, face à probabilidade de os estudantes poderem vir a enfrentar situações semelhantes na sua atividade profissional futura (Hallinger \& Bridges, 2016).

Os problemas podem, portanto, ser criações fictícias do professor, que simulem uma questão/necessidade da sociedade civil, ou a identificação, recolha e seleção de cenários reais, que se afastem de visões ideológicas sobre possíveis dificuldades encontradas na vida das pessoas, proporcionando a identificação de problemas mais contextualizados. 


\section{Um cenário de aplicação da metodologia baseada em problemas reais}

O Politécnico de Leiria é uma instituição pública de ensino superior, que se encontra na região centro de Portugal. Constituem o Politécnico cinco escolas, situadas em três cidades diferentes: a Escola Superior de Educação e Ciências Sociais, a Escola Superior de Tecnologia e Gestão e a Escola Superior de Saúde, em Leiria; a Escola Superior de Artes e Design, em Caldas da Rainha; e a Escola Superior de Turismo e Tecnologia do Mar, em Peniche. Esta instituição, com cerca de 12500 estudantes, inclui na sua oferta formativa Cursos Técnicos Superiores Profissionais (CTeSP), Pós-graduações, Licenciaturas e Mestrados.

Um dos Mestrados oferecidos pela instituição, é o Mestrado em Comunicação Acessível, criado em 2013 (Despacho n. ${ }^{\circ}$ 6606/2013) e alterado em 2016 (Despacho n. ${ }^{\circ}$ 10166/2016), que propõe, através de um olhar integrado e transdisciplinar, levar os estudantes a compreender a forma como as barreiras e estímulos ambientais, sociais, estruturais e atitudinais influenciam o processo de comunicação, considerando a diversidade de públicos. Espera-se que a formação possa contribuir para que os profissionais, das mais diversas áreas, dominem as principais teorias da comunicação, mediação e acessibilidade e conheçam ferramentas e técnicas de criação, oferta e receção de comunicação mediada.

No seu plano de estudos, este curso de 2. ${ }^{\circ}$ Ciclo inclui dez Unidades Curriculares, distribuídas por quatro semestres, sendo uma delas intitulada Inclusão na Educação, Profissão e Lazer‘. Esta unidade funciona na modalidade de Ensino à Distância e pretende ser suficientemente abrangente para criar uma panorâmica das perspetivas sob as quais se podem abordar questões de deficiência em contextos específicos da vida pessoal e social dos sujeitos. Num trabalho de articulação entre três docentes com áreas de especialização diferentes, mas complementares, espera-se contribuir para fomentar competências de análise e reflexão em torno das necessidades, condicionantes e soluções possíveis no âmbito da educação, da inclusão no mercado de trabalho e no acesso à cultura e ao lazer.

As $45 \mathrm{~h}$ da Unidade Curricular supramencionada estão organizadas em quatro atividades, sendo que nas três primeiras se espera trabalhar os conteúdos teóricos que sustentam cada uma das três áreas científicas, através da leitura de fontes bibliográficas selecionadas pelos docentes, da pesquisa autónoma de documentos de referência e do debate e reflexão colaborativa de questões e tópicos de análise lançados em fóruns de discussão.

No final destas três primeiras atividades, os estudantes devem conhecer a legislação nacional e as normas internacionais vigentes e um conjunto de diferentes medidas e estratégias de suporte à inclusão e de promoção das condições de acesso físico, social e intelectual aos bens, equipamentos e serviços associados à educação, à profíssão e ao lazer. 
O encadeamento dos conteúdos programáticos abordados evolui das questões mais abrangentes para dar lugar, numa última atividade, ao estudo de cenários e casos reais, em que se espera que sejam aplicados os conhecimentos desenvolvidos previamente. Entendese assim, tal como defende Mizokami (2018), que este tipo de estratégias permite desenvolver competências que implicam processos cognitivos externos, ou seja, uma reflexão sobre as mudanças societais, beneficiando o estudante, mas também o mundo que o rodeia.

Com este propósito é, então, lançado um último desafio aos estudantes, o de se colocarem no papel de consultores especializados em comunicação acessível e, através de um enfoque multifacetado, delinearem as respostas que a escola, os contextos profissionais e os espaços de lazer deveriam oferecer às pessoas que os frequentam. Estas pessoas são sujeitos reais, com dificuldades permanentes ao nível da comunicação, a quem devem ser dadas oportunidades de participação ativa e plena que assegurem condições para a sua autonomia e cidadania.

O ponto de partida para a resposta crítica e fundamentada, a desenvolver em pequenos grupos de trabalho, são relatórios técnicos, recolhidos a partir de uma avaliação real, que descrevem o tipo de incapacidade e o nível de funcionalidade de um(a) jovem, com idade compreendida entre os 16 e os 18 anos, trabalhor(a)-estudante. Importa referir, que estes relatórios foram devidamente codificados e adaptados antes de serem disponibilizados aos estudantes, de forma a serem respeitadas todas as questões éticas, nomeadamente a eventual capacidade de identificação dos jovens, dos técnicos ou das instituições a que pertencem.

Os relatórios incluem a idade, ano de escolaridade e profissão do sujeito, estando organizados em função das categorias da Classificação Internacional de Funcionalidade, Incapacidade e Saúde - CIF (Organização Mundial de Saúde, 2004): Funções e estruturas do corpo, Atividade e participação e Fatores ambientais. Segundo este documento, as funções do corpo dizem respeito à componente fisiológica dos sistemas orgânicos e as estruturas às partes anatómicas (ex. membros ou órgãos). A deficiência é, neste cômputo, um problema, desvio ou perda nestas componentes do corpo humano que gera modicações na forma como determinada ação ou tarefa é executada, influenciando a participação e envolvimento do sujeito em atividades diárias.

Partindo da descrição destas características, espera-se que os estudantes possam propor soluções a aplicar no ambiente físico, social e atitudinal em que a pessoa se encontra inserida, procurando reduzir as eventuais dificuldades sentidas no seu processo de inclusão social.

Tendo em conta o teor da Unidade Curricular em questão, é solicitado que cada grupo apresente propostas de ação em três áreas específicas: 
i) Resposta educativa, sendo espectável a articulação as Medidas de Suporte à Aprendizagem e Inclusão que o Decreto-Lei n. ${ }^{\circ}$ 54/2018, de 6 de julho preconiza;

ii) Resposta ao nível da profissão, aplicando ao caso concreto as regras jurídicas pertinentes, descrevendo, nomeadamente, os direitos e deveres de ambos os polos da relação jurídico-laboral;

iii) Resposta ao nível do lazer, explicitando que estratégias e práticas inclusivas podem ser desenvolvidas pelo equipamento/instituição/entidade/organismo escolhido.

O processo de ensino-aprendizagem parte, portanto, de problemas e cenários reais, tal como defendido na literatura, por se entender que esta metodologia sustenta uma componente mais prática, que se considera necessária a um bom desempenho profissional. Este tipo de casos é ainda mais relevante no caso de formações em blearning, como é o caso do Mestrado em Comunicação Acessível, em que as possibilidades de implementar ações pedagógicas concretas em contextos educativos, profissionais ou culturais, como a realização de visitas de estudo, se torna bastante mais complexa e dificultada pela distância física entre estudantes e professores. É importante realçar, a este respeito, que este Mestrado tem incluído, nas suas várias edições, estudantes de vários locais de Portugal e de países tão diferentes como o Brasil, Cabo Verde ou a Alemanha.

Ao longo da realização da atividade, os professores da Unidade Curricular assumem o papel de mediadores e orientadores, através da disponibilização de um fórum de discussão onde podem ser debatidas as questões que vão surgindo, sendo ainda um espaço de acompanhamento da construção do trabalho e do percurso formativo.

No final da atividade as várias propostas construídas pelos grupos de trabalho são partilhadas e discutidas em grande grupo, procurando-se identificar as soluções que melhor se adaptam aos problemas enfrentados pelas pessoas com deficiência, nos seus vários contextos de vida diária.

Na prática, pretende-se que os estudantes ganhem consciência de que a sua formação académica lhes pode proporcionar competências que contribuiam para mudar conceções e intervir de forma holística e reflexiva sobre os contextos reais, tornando-os mais inclusivos, acessíveis e promotores do desenvolvimento do potencial das pessoas com deficiência.

\section{Considerações finais}

A implementação de estratégias de ensino-aprendizagem que coloquem o estudante no centro do seu percurso académico e que, em simultâneo, não descurem as verdadeiras necessidades da sociedade civil, como a acessibilidade e inclusão de todos os cidadãos, 
deve ser um dos principais pressupostos do Ensino Superior. Esta metodologia carece de uma mudança de paradigma, substituindo o fim último do processo educativo, deixando-se de privilegiar a capacidade de memorização e repetição de conceitos e teorias , para passar a considerar a promoção de momentos de reflexão e análise crítica e fundamentada perante cenários reais.

Apesar de não se poderem generalizar as opções tomadas na Unidade Curricular de Inclusão na Educação, Profissão e Lazer', porque foram adotadas num contexto muito específico e com turmas que integram estudantes com perfis bastante diferenciados, acredita-se que a partilha das mesmas pode contribuir para a reflexão em torno das práticas pedagógicas implementadas no Ensino Superior. Considera-se, portanto, que a metodologia baseada em problemas (reais) potencia o conhecimento e o desenvolvimento das competências dos estudantes de nível superior, manifestadas nos resultados alcançados na avaliação contínua da Unidade Curricular e nos feedbacks qualitativos que os estudantes vão apresentando ao longo do semestre e no final da sua formação. Assume-se que estes resultados profícuos possam ser transpostos para a vida profissional dos estudantes, quer estes trabalhem em contextos diretamente relacionados com as três áreas focadas, quer exerçam as suas atividades noutros ambientes, potenciando a inclusão das pessoas com deficiência.

\section{Referências}

Barkley, E. F. (2018). Terms of engagement: understanding and promoting student engagement in today's College classroom. In K. Matsushita (Ed.), Deep Active Learning: Toward greater depth in University Education (pp. 35-57). Singapura: Springer Nature.

Burke, A. (2011). Group Work: How to Use Groups Effectively. The Journal of Effective Teaching, 11(2), 87-95.

Despacho n. ${ }^{\circ}$ 10166/2016. Alteração do Plano de Estudos do Mestrado em Comunicação Acessível. Diário da República, 2. ${ }^{a}$ série — N. ${ }^{\circ} 153$ - 10 de agosto de 2016

Despacho n. ${ }^{\circ}$ 6606/2013. Estrutura Curricular e Plano de Estudos do Ciclo de Estudos conducente ao grau de mestre em Comunicação Acessivel do Instituto Politécnico Leiria. Diário da República, 2. ${ }^{a}$ série - N. ${ }^{\circ} 97-21$ de maio de 2013

Dias, A. (2016). Ensina como eu digo e ensina como eu ensino: aplicação de metodologias de ensino aprendizagem que propiciem o apreender. Revista Fórum Identidades, 22(22), 50-70

Hallinger, P. \& Bridges, E. M. (2016). A systematic review of research on the use of problem-based learning in the preparation and development of school leaders. Educational Administration Quarterly, 1, 1-34.

Hassanien, (2006). Student Experience of Group Work and Group Assessment in Higher Education. Journal of Teaching in Travel \& Tourism, vol. 6, 17-39. 
Mangas, C. (2020). Aprendizagem Ativa no Ensino Superior: Estratégias Pedagógicas para um Trabalho Colaborativo. Millenium, 2(12), 59-65

Mizokami, S. (2018). Deep active learning from perspectives of active learning theory. In K. Matsushita (ed.), Deep Active Learning: Toward greater depth in University Education (pp. 7991). Singapura: Springer Nature

Moran, J. M. (2015). Mudando a educação com metodologias ativas. In: C. Souza; O. Morales (Orgs.). Convergências midiáticas, educação e cidadania: aproximações jovens (pp. 15-33). Ponta Grossa: Foca Foto-PROEX/UEPG

Omete, S. (2018). Atitudes Sociais em Relação à Inclusão: Recentes Avanços em Pesquisa. Rev. Bras. Ed. Esp., 24, Edição Especial, 21-32.

Organização Mundial da Saúde. (2004). Classificação internacional de funcionalidade, incapacidade e saúde (CIF). Lisboa: Direcção Geral da Saúde

Sassaki, R. K. (2009, março/abril). Inclusão: acessibilidade no lazer, trabalho e educação. Revista Nacional de Reabilitação (Reação), 10-16.

Skoog, C. (2017). Leaving no child with disability behind. Salud Pública de México, 59, 4, 349-350

Suleman, F. (2016). Employability skills of higher education graduates: Little consensus on a muchdiscussed subject. Procedia - Social and Behavioral Sciences, 228, 169-174.

Ülger, Z., Dette-Agenmeyer, D. E., Reichle, B. \& Gaertner, S. L. (2018). Improving outgroup attitudes in schools: a meta-analytic review. Journal of School Psychology, 67, 88-103.

Yew, E. H. J. \& Goh, K. (2016). Problem based learning: An overview of its process and impact on learning. Health Professions Education, 2, 75-79. 